\title{
Novel sphincterotomy device that orientates blade along the axis of the bile duct in patients with Roux-en-Y anastomosis
}
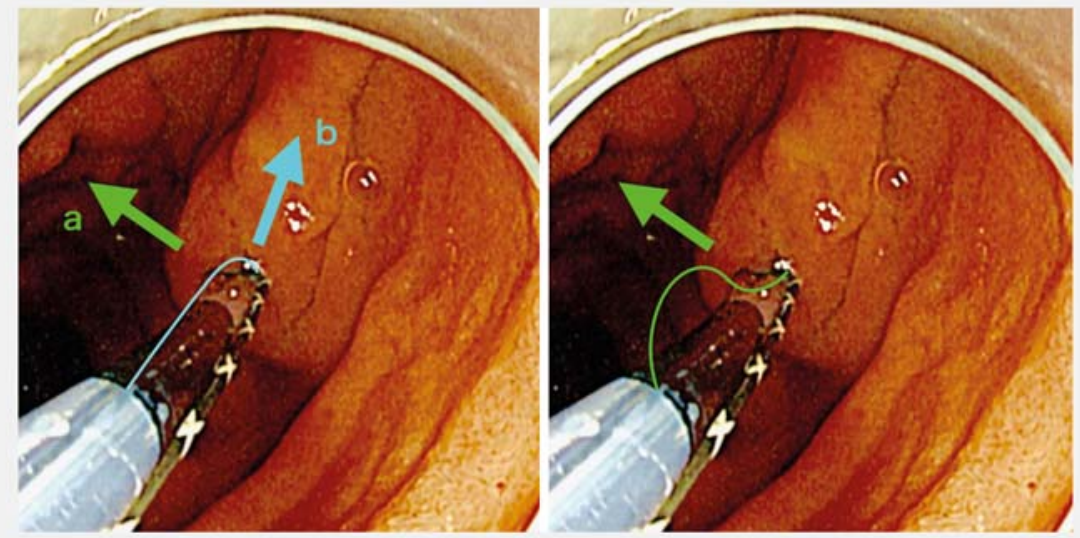

- Fig. 1 Orientation for endoscopic sphincterotomy in patients with Roux-en-Y anastomosis. Left panel: with the conventional sphincterotomy approach, the direction of the blade (arrow b) does not correspond with the correct incision direction (arrow a; axis of the bile duct). Right panel: a blade oriented in the appropriate incision direction (arrow) is desirable in these patients.
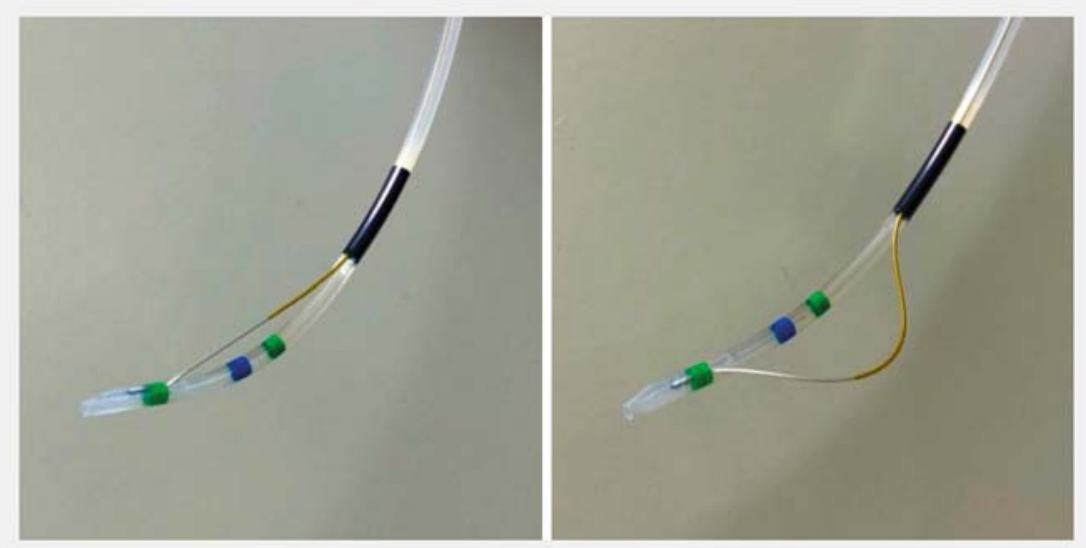

- Fig. 2 The Correctome (Boston Scientific, Marlborough, Massachusetts, USA) is a new sphincterotomy device that allows optimal orientation of the blade. Left panel: the blade can be stretched for the conventional sphincterotomy approach. Right panel: the blade can be loosened in the opposite direction.

Endoscopic papillary large balloon dilation (EPLBD) following endoscopic sphincterotomy (EST) is an effective and safe treatment for common bile duct (CBD) stones in patients with Roux-en-Y anastomosis [1, 2]. However, performing EST using the conventional sphincterot- omy approach in these patients is considered difficult because it has to be done in the opposite direction $[3,4]$. The direction of the blade does not correspond with the correct incision direction (axis of the bile duct) in this situation. It is desirable, therefore, for the blade to be

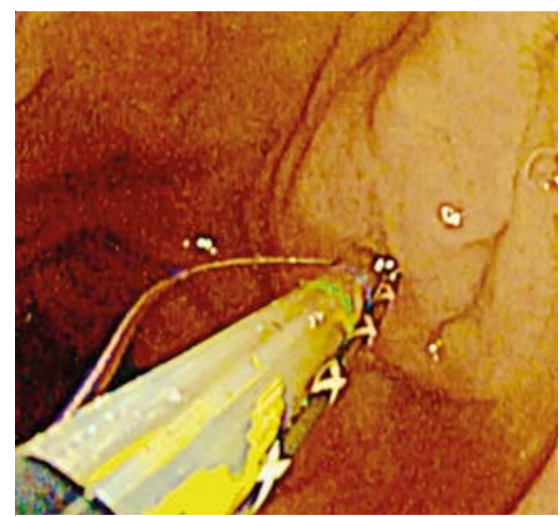

- Fig. 3 The Correctome (Boston Scientific, Marlborough, Massachusetts, USA) was intubated into the papilla over the guidewire, and the blade was loosened to achieve wide bowing. The direction of the blade was turned towards the bile duct axis without any adjustment.

oriented in the appropriate incision direction in patients with Roux-en-Y anastomosis ( Fig. 1).

The Correctome (Boston Scientific, Marlborough, Massachusetts, USA) is a new sphincterotomy device that allows optimal orientation of the blade. The blade of the Correctome can be stretched for the conventional sphincterotomy approach. Furthermore, this blade can be loosened in the opposite direction, resulting in wide bowing ( $\triangleright$ Fig. 2).

A 69-year-old man who had undergone total gastrectomy with Roux-en-Y anastomosis was admitted to our hospital for the treatment of $C B D$ stones. A shorttype single-balloon enteroscope (SIFH290; Olympus Medical Systems, Tokyo, Japan) was inserted into the papilla, and selective biliary cannulation was successfully performed [5]. Next, the Correctome was intubated into the papilla over the guidewire, and the blade was loosened to achieve wide bowing. The direction of the blade was turned towards the bile duct axis without any adjustment ( Fig.3). The opening to the ampulla was enlarged by cutting ( $>$ Fig. 4 ), and 

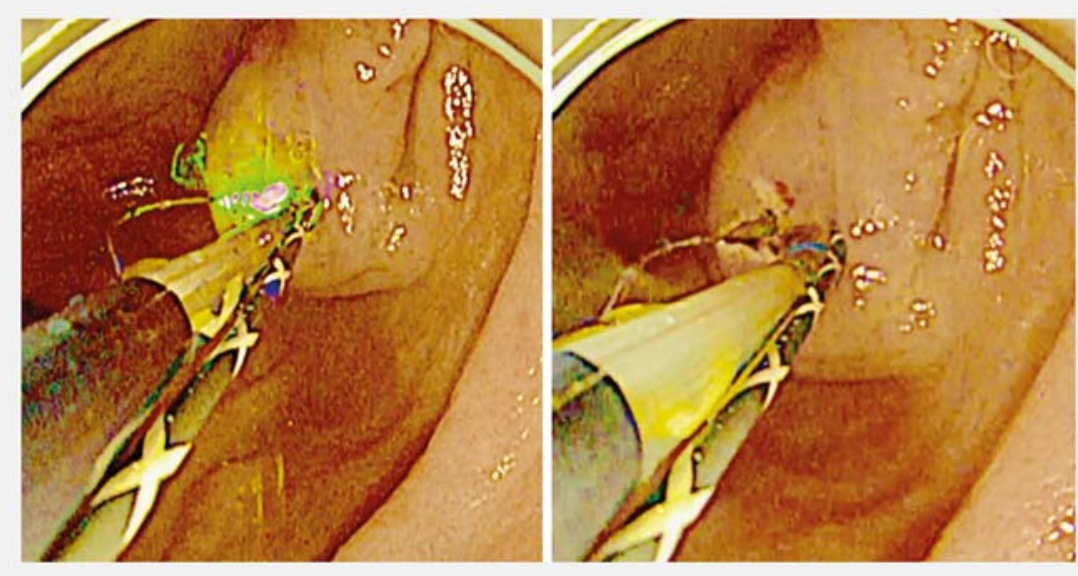

Fig. 4 The opening to the ampulla was enlarged by cutting.
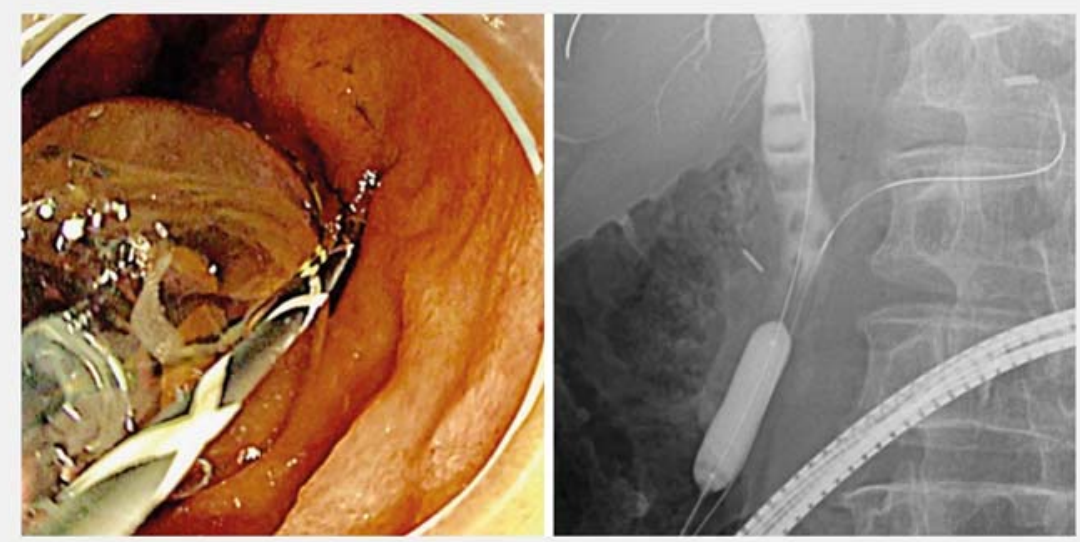

- Fig.5 After endoscopic sphincterotomy, endoscopic papillary large balloon dilation was performed. All stones were successfully removed. Left panel: endoscopic image. Right panel: fluoroscopic image.
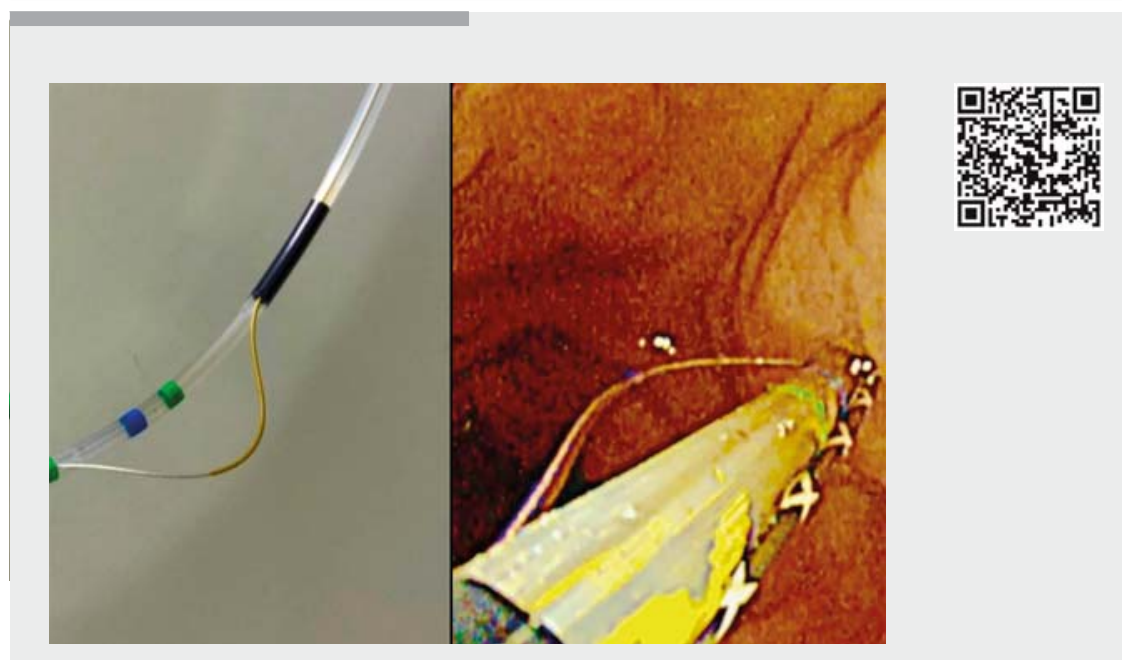

Video 1 Novel sphincterotomy approach with blade that can be oriented along the axis of the bile duct in patients with Roux-en-Y anastomosis.
EPLBD was performed ( $\mathbf{F i g . 5}$ ). All stones were successfully removed.

This novel sphincterotomy device that allows orientation of the blade along the axis of the bile duct is considered useful for EST, not only for patients with normal anatomy but also for patients with Rouxen-Y anastomosis ( $\triangleright$ Video 1 ).

Endoscopy_UCTN_Code_TTT_1AS_2AG

Competing interests

None

The authors

Mamoru Takenaka, Tomoe Yoshikawa, Ayana Okamoto, Atsushi Nakai, Kosuke Minaga, Kentaro Yamao, Masatoshi Kudo

Department of Gastroenterology and Hepatology, Kindai University Faculty of Medicine, Osaka-Sayama, Japan

\section{Corresponding author}

\section{Mamoru Takenaka, MD}

Department of Gastroenterology and Hepatology, Kindai University Faculty of Medicine, 377-2 Ohno-Higashi, OsakaSayama 589-8511, Japan

Fax: +81-72-3672880

mamoxyo45@gmail.com

\section{References}

[1] Itoi T, Ishii K, Sofuni A et al. Large balloon dilatation following endoscopic sphincterotomy using a balloon enteroscope for the bile duct stone extractions in patients with Roux-en-Y anastomosis. Dig Liver Dis 2011; 43: $237-241$

[2] Nakai Y, Kogure H, Yamada A et al. Endoscopic management of bile duct stones in patients with surgically altered anatomy. Dig Endosc 2018; 30 (Suppl. 01): 67-74

[3] Hintze RE, Adler A, Veltzke W et al. Endoscopic access to the papilla of Vater for endoscopic retrograde cholangiopancreatography in patients with Billroth II or Rouxen-Y gastrojejunostomy. Endoscopy 1997; 29: $69-73$ 
[4] Yane K, Katanuma A, Maguchi H et al. Shorttype single-balloon enteroscope-assisted ERCP in postsurgical altered anatomy: potential factors affecting procedural failure. Endoscopy 2017; 49: 69-74

[5] Takenaka M, Yamao K, Kudo M. A novel method of biliary cannulation for patients with Roux-en-Y anastomosis using a unique, uneven, double lumen cannula (uneven method). Dig Endosc 2018; 30: 808-809

\section{Bibliography}

DOI https://doi.org/10.1055/a-0858-9831

Published online: 25.3.2019

Endoscopy 2019; 51: E132-E134

(c) Georg Thieme Verlag KG

Stuttgart · New York

ISSN 0013-726X

\section{ENDOSCOPY E-VIDEOS}

https://eref.thieme.de/e-videos

回的 Endoscopy E-Videos is a free access online section, reporting 靣: on interesting cases and new techniques in gastroenterological endoscopy. All papers include a high quality video and all contributions are freely accessible online.

This section has its own submission website at

https://mc.manuscriptcentral.com/e-videos 